\title{
Development and Analysis of a High Thrust Force Direct-Drive Linear Actuator
}

\author{
Yasutaka Fujimoto, Member, IEEE, Tsutomu Kominami, and Hiroshi Hamada
}

\begin{abstract}
This paper presents design and analysis of a novel high thrust force linear actuator with high backdrivability. This motor consists of a mover and stator with spiral (helical) structure. The mover moves spirally in the stator and the linear motion is extracted to drive the load. This motor is a direct-drive system and highly backdrivable. In this paper, a basic model and thrust-force/torque equations are proposed, and FEM analysis and experimental results of a prototype are presented. From experiments, the designed spiral motor achieves $2000[\mathrm{~N}]$ rated thrust force. The thrust force capabilities of the spiral motor are compared with other linear motors. It is confirmed that the spiral motor is almost close to the latest state-of-the-art in linear motor technology.
\end{abstract}

\section{NOMENCLATURE}

$\alpha \quad$ angle of a sector-type permanent magnet

$B_{r} \quad$ residual flux density of a permanent magnet

$c(\theta) \quad$ a spatial distribution for magnetomotive force of a permanent magnet

$f \quad$ thrust force of the mover

$f_{w . b . s .} \quad$ thrust force of the mover with a ballscrew

$I \quad=\left[I_{u}, I_{v}, I_{w}\right]^{T}$, three-phase currents on forward side windings in Y-connection

$I^{\prime} \quad=\left[I_{u}^{\prime}, I_{v}^{\prime}, I_{w}^{\prime}\right]^{T}$, three-phase currents on backward side windings in Y-connection

$I_{m} \quad$ magnetomotive force of a permanent magnet

$I_{i} \quad i$-axis current on forward side windings, $i \in\{d, q\}$

$I_{i}^{\prime} \quad i$-axis current on backward side windings, $i \in\{d, q\}$

$J$ moment of inertia of the mover around the axis

$k$ a fundamental Fourier component of $c(\theta)$

$K_{f} \quad$ a thrust force constant

$\ell \quad$ a nominal gap between the mover iron and the stator

$\ell_{g} \quad$ nominal length of air gap

$\ell_{m} \quad$ width of magnet

$\ell_{p} \quad$ lead length of screw

$\ell_{p m} \quad$ length of one pitch mover

$\ell_{p s} \quad$ length of one pitch stator

$\mu_{0} \quad$ the permeability in vacuum

$\mu_{m} \quad$ permeability of a permanent magnet

$M \quad$ mass of the mover

$n \quad$ a number of turns of windings

Manuscript received May 15, 2008; revised October 4, 2008. Accepted for publication November 13, 2008. This work was supported by KAKENHI 19676003 and by NEDO 05A48701d.

Copyright (C) 2009 IEEE. Personal use of this material is permitted. However, permission to use this material for any other purposes must be obtained from the IEEE by sending a request to pubs-permissions@ieee.org

Authors are with the Department of Electrical and Computer Engineering, Yokohama National University, Yokohama 240-8501 Japan (e-mail: fujimoto@ynu.ac.jp). $p \quad$ number of pole pairs per 360 degree electric angular displacement

$\Phi_{i} \quad$ interlinkage flux for current $I_{i}, i \in\{u, v, w\}$

$\Phi_{i}^{\prime} \quad$ interlinkage flux for current $I_{i}^{\prime}, i \in\{u, v, w\}$

$q \quad$ number of layers

$\theta \quad$ mechanical rotational angle of the mover

$R_{g} \quad$ magnetic resistance of forward side air gap for an area of a phase winding

$R_{g}^{\prime} \quad$ magnetic resistance of backward side air gap for an area of a phase winding

$R_{m} \quad$ magnetic resistance of a permanent magnet

$r_{1} \quad$ inner radius of a permanent magnet

$r_{2} \quad$ outer radius of a permanent magnet

$r_{a}$ radius of inner the axis

$r_{b} \quad$ outer radius of the mover

$S \quad$ a gap area per 360 degree mechanical angle displacement

$\tau \quad$ torque of the mover

$P \quad$ permeance of forward side air gap between the mover iron and the stator

$P^{\prime} \quad$ permeance of backward side air gap between the mover iron and the stator

$W_{m}^{\prime} \quad$ the magnetic coenergy

$x \quad$ a linear position of the mover

$x_{g} \quad$ displacement of air gap

\section{INTRODUCTION}

C OMBINATION of servo motors and high-ratio gears such as harmonic gears is widely used in robotic applications. Because the electric motor has high-velocity and low-torque characteristics, the output of the motor is reduced by high-ratio gears. However, loss of torque and output power occurs during their transmission by the gears. The joint of robots becomes non-backdrivable due to the highratio gears. The non-backdrivability causes lack of adaptability and safety. Various joint mechanisms and controls that recover the backdrivability were reported in the past works [1][10]. The direct-drive system, firstly reported in [1], avoids friction loss and realizes good controllability, but the mass and volume of the joint becomes too big. Torque sensorless control for a direct-drive manipulator based on disturbance observer was proposed in [2]. Another sensorless force control for a manipulator with geared actuators was reported in [3]. Moreover, an accelerometer improves performance of the disturbance observer [5]. The twin-drive system reported in [6] cancels the static friction of two geared motors each other by using a differential gear system. The static friction does not appear in the total output of the joint system. Some actuators 
put elastic mechanism between the output and gears [7][10]. The elasticity improves stability and safety but decreases controllability in high frequency domain. A two stage actuator system [8] overcomes this drawback but the system becomes complicated.

From the viewpoint of controllability, the direct-drive systems are suitable for robotic applications because they are almost free from backlash and friction and easy to realize precise, high-speed, and safe motion. However, conventional direct-drive systems including linear motors are relatively big for such applications.

In this paper, a novel linear actuator with spiral structure is proposed. The motor consists of a spiral stator and a spiral mover with permanent magnet. The mover almost does not contact the stator and moves spirally in the stator under a proper gap control. Thus, the motor realizes direct-drive motion. Also the motor has high thrust force characteristics because flux of the motor is effectively utilized in its three dimensional structure.

On the other hand, several types of linear motors have been developed[11]-[34] recently. A high thrust density linear (HDL) motor which has permanent magnets inside the mover teeth have been proposed in [19]-[21]. From a viewpoint of a thrust force per air-gap area, it was reported that the HDL can generate a thrust force two times higher than a linear permanent magnet synchronous motor and six times than a linear induction motor[20].

Another type of high thrust force linear motor; tubular linear permanent magnet (TL-PM) motor was reported in [11][14],[22]-[25]. The design optimization and magnet arrangement of the TL-PM was discussed in [22] and the quasiHalbach magnetized magnet type was developed in [23]-[25]. Comparisons among different TL-PM motor configurations were reported in [12].

Articles [27]-[33] present various types of a helical motion motor which is a two-degree-of-freedom actuator capable of producing rotary motion, linear motion, or helical motion. There are induction-type motor[27]-[30], reluctancetype motor[31], and permanent-magnet-type motor[32],[33]. Another variation is a one-degree-of-freedom actuator with rotary-type stepping motor drive system applied to a mover with double-helical permanent magnet[34]. All these helical motors are radial-gap motor.

The motor proposed in this paper is an axial-gap helical motion permanent magnet motor, which is completely different from any linear motors mentioned above. Due to its large air-gap area, the motor can generate relatively high thrust force. The rest of the paper is organized as follows. A basic permeance model of the spiral motor is proposed and the thrust force characteristics are derived in the section II. Then, a first prototype of the motor is introduced in the section III. Numerical analyses of thrust force for the prototype are reported in the section IV. They are compared with experimentally measured thrust force in the section V. Comparisons with other linear motors show in the section VI that the spiral motor has almost same thrust force capabilities as latest state-of-art linear motors. The section VII concludes the paper.

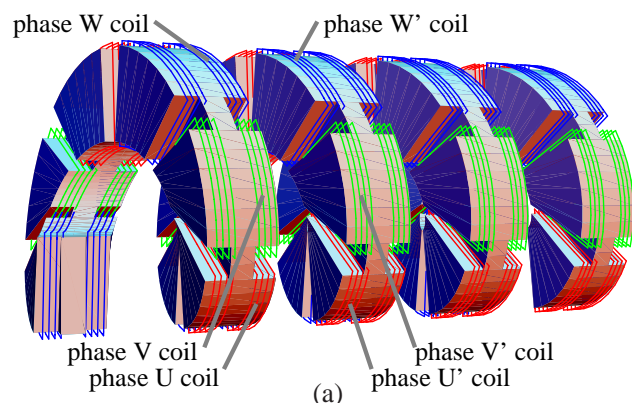

(a)

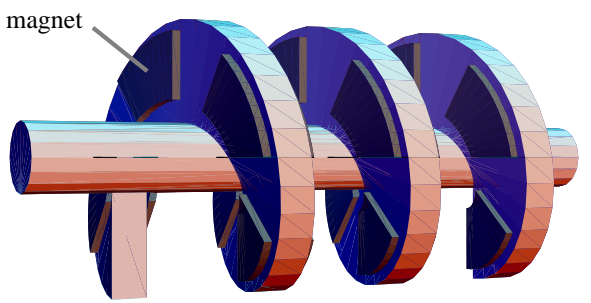

(b)

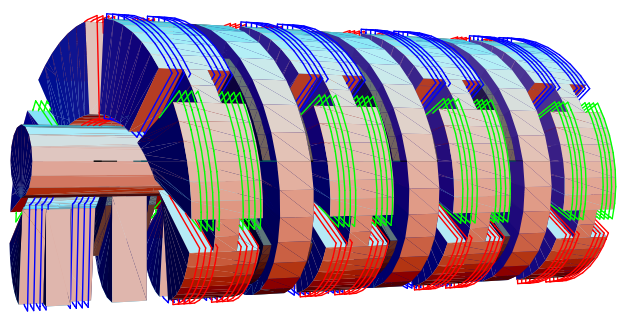

(c)

Fig. 1. A preliminary structure of a spiral motor. (a) A stator with threephase windings. (b) A mover with permanent magnets. (c) A motor combined with the stator and mover.

\section{Analytical EQuations}

In this section, a preliminary structure and an idealized permeance model of the motor are presented. Using the permeance model, thrust-force/torque equations are derived. These equations show the dependence of the motor performance on specific parameters.

\section{A. Structure of Motor}

Figure 1 shows a preliminary structure of the spiral motor. Permanent magnets are attached on the surfaces of the mover. Slots are also provided for winding on the surface of the stator. Three-phase winding in the slots generates flux in the axial direction. The structure of the spiral motor is shown in Fig. 2. The radial load of the mover is supported by two slide rotary bushes and the thrust load is directly controlled by the electromagnetic force.

\section{B. Permeance Model of Motor}

In order to derive analytical thrust-force and torque equations, a permeance model of the motor for 360 degree electric angular displacement in polar coordinates is presented.

Figure 3 shows the polar coordinates expression of the motor. From this model, a simple magnetic circuit as shown in Fig. 4 is obtained. $R_{g}=3 p\left(\ell_{g}-x_{g}\right) / S \mu_{0}$ is magnetic 


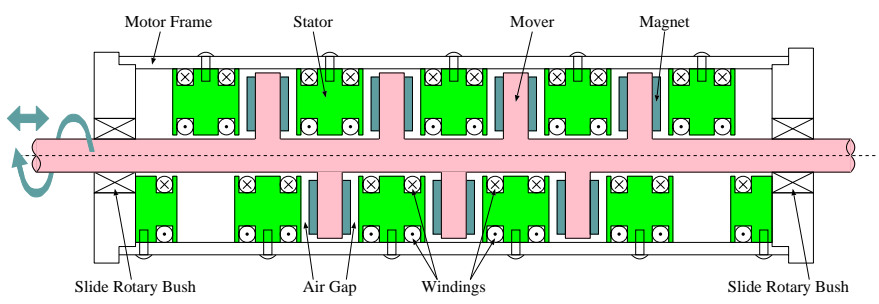

Fig. 2. A structure of a spiral motor.

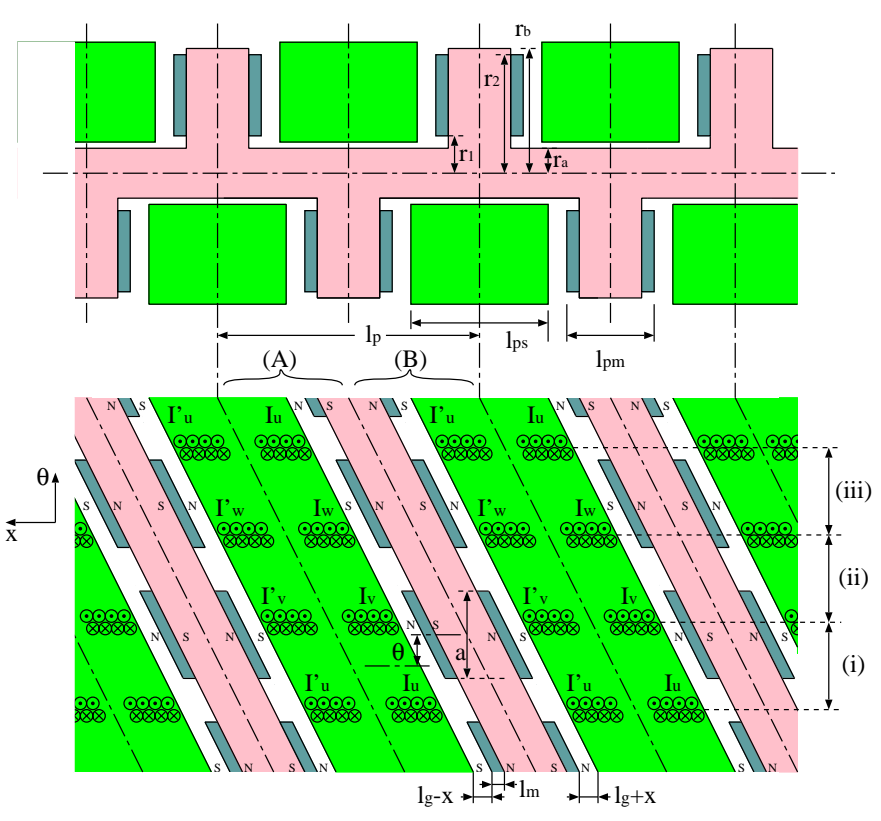

Fig. 3. A spiral motor in polar coordinates.

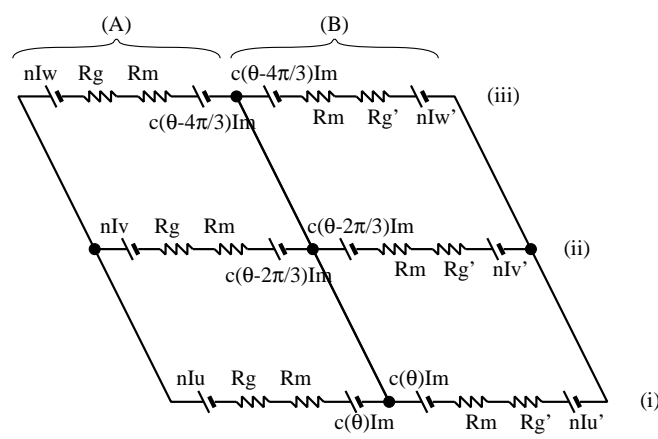

Fig. 4. A magnetic circuit.

resistance of forward side air gap for an area of each phase winding, where $S=\pi\left(r_{2}{ }^{2}-r_{1}{ }^{2}\right)$ is an area of the cross section of the cylinder. $R_{g}^{\prime}=3 p\left(\ell_{g}+x_{g}\right) / S \mu_{0}$ is magnetic resistance of backward side air gap. $R_{m}=3 p \ell_{m} / S \mu_{m}$ is magnetic resistance of a permanent magnet. $c(\cdot) I_{m}$ is a spatial function of magnetomotive force of the permanent magnet. For simplicity, we assume that the permeability of the permanent magnet $\mu_{m}$ is equivalent to $\mu_{0}$. Also the edge effect is ignored.

From this magnetic circuit, interlinkage flux for each current is given as follows.

$$
\Phi_{u}=n P\left(c(p \theta) I_{m}+n I_{u}\right)
$$

$$
\begin{aligned}
\Phi_{v}= & n P\left(c\left(p \theta-\frac{2 \pi}{3}\right) I_{m}+n I_{v}\right) \\
\Phi_{w}= & n P\left(c\left(p \theta-\frac{4 \pi}{3}\right) I_{m}+n I_{w}\right) \\
\Phi_{m}= & P\left(\frac{3 p \alpha}{2 \pi} I_{m}+n c(p \theta) I_{u}\right. \\
& \left.+n c\left(p \theta-\frac{2 \pi}{3}\right) I_{v}+n c\left(p \theta-\frac{4 \pi}{3}\right) I_{w}\right) \\
\Phi_{u}^{\prime}= & n P^{\prime}\left(c(p \theta) I_{m}+n I_{u}^{\prime}\right) \\
\Phi_{v}^{\prime}= & n P^{\prime}\left(c\left(p \theta-\frac{2 \pi}{3}\right) I_{m}+n I_{v}^{\prime}\right) \\
\Phi_{w}^{\prime}= & n P^{\prime}\left(c\left(p \theta-\frac{4 \pi}{3}\right) I_{m}+n I_{w}^{\prime}\right) \\
\Phi_{m}^{\prime}= & P^{\prime}\left(\frac{3 p \alpha}{2 \pi} I_{m}+n c(p \theta) I_{u}^{\prime}\right. \\
& \left.+n c\left(p \theta-\frac{2 \pi}{3}\right) I_{v}^{\prime}+n c\left(p \theta-\frac{4 \pi}{3}\right) I_{w}^{\prime}\right)
\end{aligned}
$$

where $P=1 /\left(R_{g}+R_{m}\right)=S \mu_{0} /\left(3 p\left(\ell-x_{g}\right)\right)$ is permeance of forward side air gap between the mover iron and the stator, $P^{\prime}=1 /\left(R_{g}^{\prime}+R_{m}\right)=S \mu_{0} /\left(3 p\left(\ell+x_{g}\right)\right)$ is permeance of backward side air gap between the mover iron and the stator, and $\ell=\ell_{g}+\ell_{m}$ is a nominal gap between the mover iron and the stator. $I_{m}=B_{r} \ell_{m} / \mu_{m}$ is an equivalent magnetization current, i. e., magnetomotive force of the permanent magnet.

For simplicity, the spatial function $c(\theta)$ approximates a cosine function as follows.

$$
c(\theta)=k \cos (\theta)
$$

where $k=\frac{6 \sqrt{3}}{\pi^{2}} \sin (p \alpha / 2)$ is the fundamental component of $c(\theta)$.

\section{Thrust-Force and Torque Equations}

The magnetic coenergy of whole system is given by

$$
\begin{aligned}
W_{m}^{\prime}= & \frac{p q}{2}\left(\Phi_{u} I_{u}+\Phi_{v} I_{v}+\Phi_{w} I_{w}+\Phi_{m} I_{m}\right. \\
& \left.+\Phi_{u}^{\prime} I_{u}^{\prime}+\Phi_{v}^{\prime} I_{v}^{\prime}+\Phi_{w}^{\prime} I_{w}^{\prime}+\Phi_{m}^{\prime} I_{m}^{\prime}\right) \\
= & \frac{q S \mu_{0}}{3\left(\ell-x_{g}\right)}\left(\frac{3 p \alpha I_{m}^{2}}{4 \pi}+\frac{n^{2}}{2}\left(I_{u}^{2}+I_{v}^{2}+I_{w}^{2}\right)\right. \\
+ & \left.k n I_{m}\left(I_{u} \cos p \theta+I_{v} \cos \left(p \theta-\frac{2 \pi}{3}\right)+I_{w}\left(p \theta-\frac{4 \pi}{3}\right)\right)\right) \\
+ & \frac{q S \mu_{0}}{3\left(\ell+x_{g}\right)}\left(\frac{3 p \alpha I_{m}^{2}}{4 \pi}+\frac{n^{2}}{2}\left(I_{u}^{\prime 2}+{I_{v}^{\prime}}^{2}+I_{w}^{\prime 2}\right)\right. \\
+ & \left.k n I_{m}\left(I_{u}^{\prime} \cos p \theta+I_{v}^{\prime} \cos \left(p \theta-\frac{2 \pi}{3}\right)+I_{w}^{\prime}\left(p \theta-\frac{4 \pi}{3}\right)\right)\right) .
\end{aligned}
$$

The displacement of the gap between the mover and the stator holds the following relation

$$
x_{g}=x-\frac{\ell_{p}}{2 \pi} \theta
$$

where $x$ is a linear position of the mover. Therefore, the thrust force and the torque are given by

$$
\begin{aligned}
f & =\frac{d W_{m}^{\prime}}{d x}=\frac{\partial W_{m}^{\prime}}{\partial x_{g}} \\
\tau & =\frac{d W_{m}^{\prime}}{d \theta}=\frac{\partial W_{m}^{\prime}}{\partial \theta}+\frac{d x_{g}}{d \theta} \frac{\partial W_{m}^{\prime}}{\partial x_{g}}
\end{aligned}
$$


Assume that three-phase currents is represented by d-axis currents $I_{d}, I_{d}^{\prime}$ and q-axis currents $I_{q}, I_{q}^{\prime}$ as follows.

$$
\begin{aligned}
I_{u} & =I_{d} \cos (p \theta)-I_{q} \sin (p \theta) \\
I_{v} & =I_{d} \cos \left(p \theta-\frac{2 \pi}{3}\right)-I_{q} \sin \left(p \theta-\frac{2 \pi}{3}\right) \\
I_{w} & =I_{d} \cos \left(p \theta-\frac{4 \pi}{3}\right)-I_{q} \sin \left(p \theta-\frac{4 \pi}{3}\right) \\
I_{u}^{\prime} & =I_{d}^{\prime} \cos (p \theta)-I_{d}^{\prime} \sin (p \theta) \\
I_{v}^{\prime} & =I_{d}^{\prime} \cos \left(p \theta-\frac{2 \pi}{3}\right)-I_{q}^{\prime} \sin \left(p \theta-\frac{2 \pi}{3}\right) \\
I_{w}^{\prime} & =I_{d}^{\prime} \cos \left(p \theta-\frac{4 \pi}{3}\right)-I_{q}^{\prime} \sin \left(p \theta-\frac{4 \pi}{3}\right) .
\end{aligned}
$$

From (12)-(19), the thrust force and the torque are rewritten as follows.

$$
\begin{aligned}
f= & \frac{q S \mu_{0}}{2}\left(\frac{2 p \alpha I_{m}^{2} \ell}{\pi\left(\ell-x_{g}\right)^{2}\left(\ell+x_{g}\right)^{2}} x_{g}\right. \\
& +n k I_{m}\left(\frac{I_{d}}{\left(\ell-x_{g}\right)^{2}}-\frac{I_{d}^{\prime}}{\left(\ell+x_{g}\right)^{2}}\right) \\
& \left.+\frac{n^{2}}{2}\left(\frac{I_{d}^{2}+I_{q}^{2}}{\left(\ell-x_{g}\right)^{2}}-\frac{I_{d}^{\prime 2}+I_{q}^{\prime 2}}{\left(\ell+x_{g}\right)^{2}}\right)\right) \\
\tau= & \frac{p q n S \mu_{0} k I_{m}}{2}\left(\frac{I_{q}}{\ell-x_{g}}+\frac{I_{q}^{\prime}}{\ell+x_{g}}\right)-\frac{\ell_{p}}{2 \pi} f .
\end{aligned}
$$

From these analyses, it turns out that $\mathrm{d}$-axis currents mainly affects thrust force and q-axis currents mainly affects torque.

In order to control the gap $x_{g}$, the mover rotation angle $\theta$ is actively controlled by the torque $\tau$. Under a proper gap control against load fluctuation, full direct-drive motion is achieved. The concept is similar to magnetic levitation control. For the case of rotational motors, this corresponds to bearingless drives [35][36].

\section{Thrust Equation for Simplified Motor Structure}

The gap control is not necessary and $x_{g}=0$ holds if we introduce a ballscrew at the axis of the mover as shown in Fig. 5. This system still has quasi-direct-drive feature. Our first prototype described in the next section is in this case. The total thrust force is a combination of the directly generated thrust (20) and that derived from the action of the ballscrew, which transforms the torque (21) into the thrust force. The total thrust force equation is obtained as follows.

$$
f_{w . b . s .}=f+\frac{2 \pi}{\ell_{p}} \tau=\frac{\pi p q n S \mu_{0} k I_{m}}{\ell_{p} \ell}\left(I_{q}+I_{q}^{\prime}\right) .
$$

The first term corresponds to the direct thrust force. The second term corresponds to the thrust force from the ballscrew and is derived from the principle of virtual work. As a result, the first term is cancelled and the first term in the torque equation (21) remains. Hence, the only q-axis component of currents affects the total thrust force. This is only the case that the ballscrew is applied in order to omit gap control. Otherwise, (20) becomes the total thrust force.

Assuming a series connection of the forward and backward side windings, it yields $I_{q}^{\prime}=I_{q}$ and

$$
f_{w . b . s .}=K_{f} I_{q}
$$

where $K_{f}=2 \pi p q n S \mu_{0} k I_{m} / \ell_{p} \ell$ is a thrust force constant.

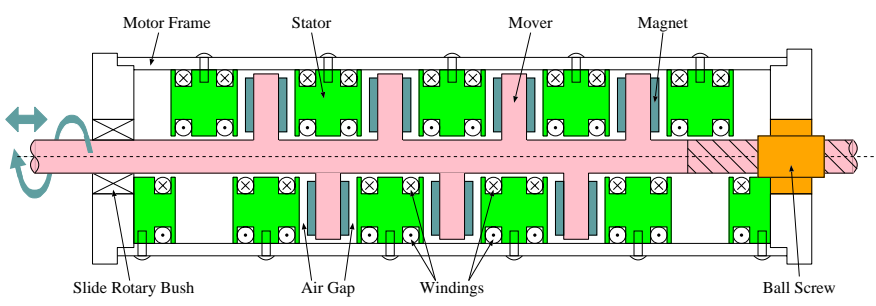

Fig. 5. A spiral motor with a ballscrew.

TABLE I

SPECIFICATIONS OF THE PROTOTYPE.

\begin{tabular}{ll}
\hline Size & $424 \times 204 \times 178[\mathrm{~mm}]$ \\
Weight & $43[\mathrm{~kg}]$ \\
Stroke & $95[\mathrm{~mm}]$ \\
Resistance of windings & $2.8[\Omega]$ \\
d-axis inductance & $7.49[\mathrm{mH}]$ \\
q-axis inductance & $7.82[\mathrm{mH}]$ \\
Number of turns $n$ & 39 \\
$p ;$ Number of pole pairs & 2 \\
$q$; Number of layers & 6 \\
$\ell_{g} ;$ Nominal gap & $2[\mathrm{~mm}]$ \\
$\ell_{m} ;$ Width of magnet & $2[\mathrm{~mm}]$ \\
$\ell_{p} ;$ Lead length of screw & $30[\mathrm{~mm}]$ \\
$B_{r} ;$ Residual flux density & $1.21[\mathrm{~T}]$ \\
$S ;$ Area of the cross section & $9.45 \times 10^{3}\left[\mathrm{~mm}^{2}\right]$ \\
Area of a slot & $50\left[\mathrm{~mm}{ }^{2}\right]$ \\
Diameter of wire & $0.8[\mathrm{~mm}]$ \\
\hline
\end{tabular}

\section{Development of a Prototype}

The structure of the proposed spiral motor is very complicated. Thus, we have designed unit components of the mover and stator. The mover and stator units are shown in Fig. 6(a). The mover unit has two magnets on its surfaces. The stator unit equips two windings. The surfaces of these unit are almost flat and the units are possible to manufacture easily. Figure 6(b) and (c) show the assembled mover and stator. The spiral structures are approximately realized by combining these units.

The photos of the developed components are shown in Fig. 7. Figure 7(a) shows the outline of the prototype. The mover and stator units are shown in Fig. 7(b). Two Nd-Fe$\mathrm{B}$ magnets are on the surfaces of the mover unit. The iron core of the stator unit is made by Si steel plate. Figure 7(c) shows the inner structure of the prototype. The specifications of this prototype is shown in Table I. A ballscrew is attached at one side of the axis for this prototype as shown in Fig. 5 to control the mover easily. A slide rotary bush supports radial load on another side of the axis. The slide rotary bush made by Nippon Bearing Co., Ltd. provides both endless smooth rotary and linear motion functions utilizing ball elements and ball-holding retainer between a cylindrical steel outer race and the shaft.

Figure 8 shows a rotation cancellation mechanism for the output axis of the proposed motor when only translational motion is needed in linear applications. This mechanism is attached at the tip of the output axis of the prototype as shown in Fig. 7(a). 


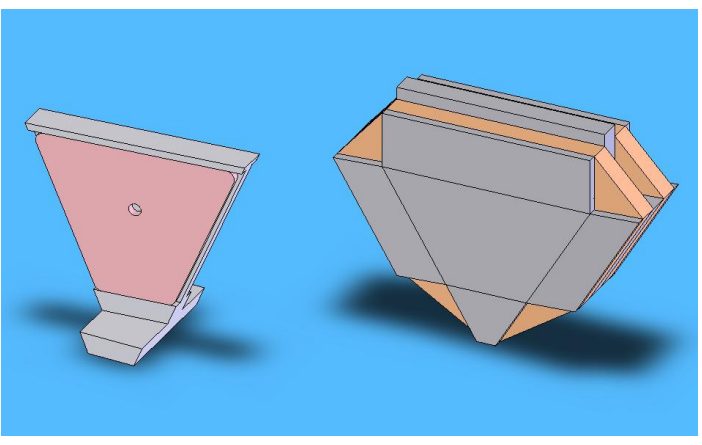

(a)

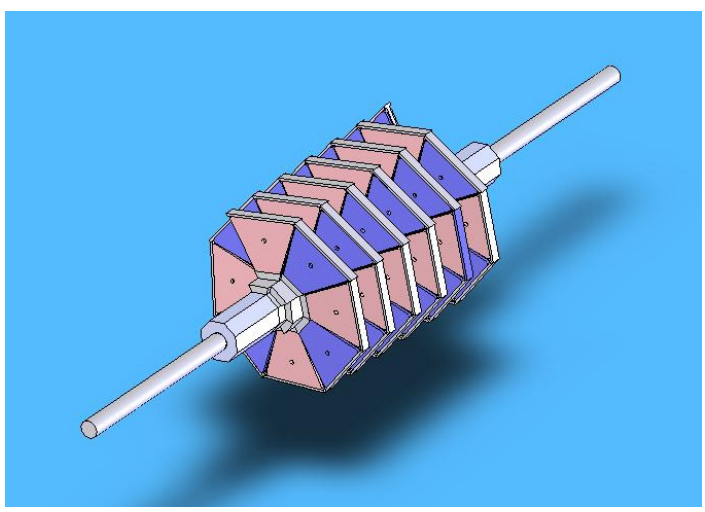

(b)

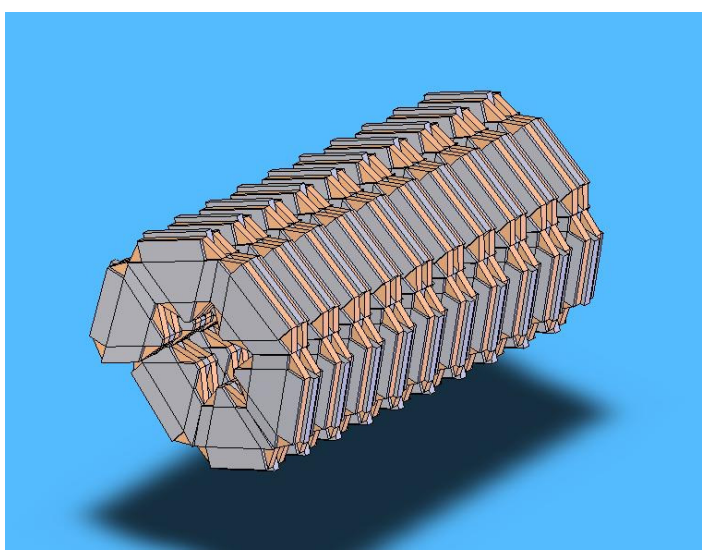

(c)

Fig. 6. Design sketches of the prototype. (a) Mover block (left) and stator block (right). (b) Combined mover. (c) Combined stator.

\section{NUMERICAL ANALYSIS}

\section{A. Permeance Analysis}

Based on the basic model described above, expected performance is calculated as follows. The calculated thrust force constant using parameters in Table I becomes 590 [N/A]. The maximum thrust force is obtained from a heat condition. The copper loss and heat transfer is considered but iron loss is neglected. The space factor of the windings is assumed to be $40 \%$. The operation atmosphere temperature is up to 40 [deg C] and windings temperature is up to 140 [deg C]. The convection heat transfer coefficient is assumed to be 10 $\left[\mathrm{W} / \mathrm{m}^{2} \mathrm{~K}\right]$. The resulting rated thrust force is $2310[\mathrm{~N}]$ as shown in Table II. These are under the continuous operating condition.

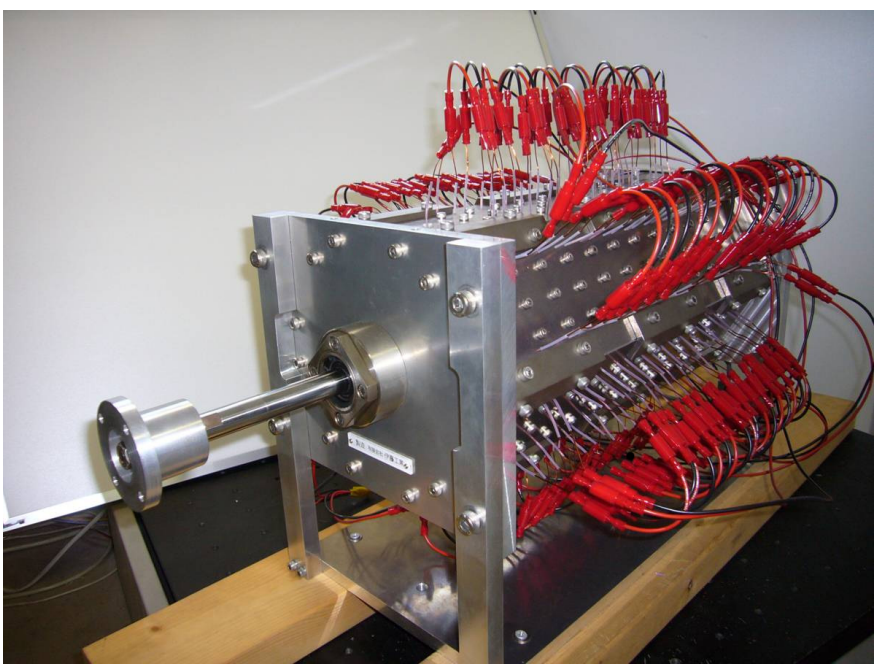

(a)

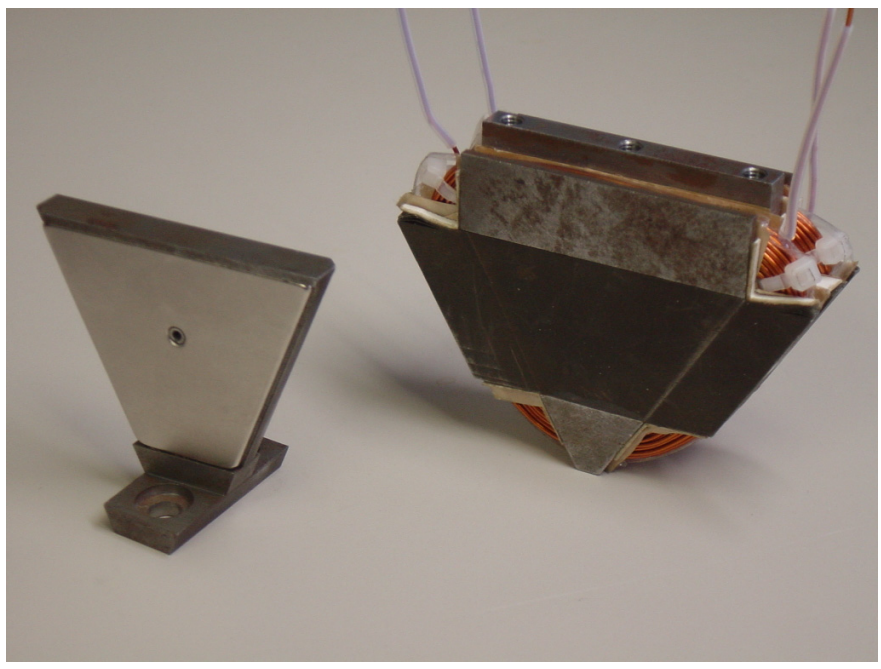

(b)

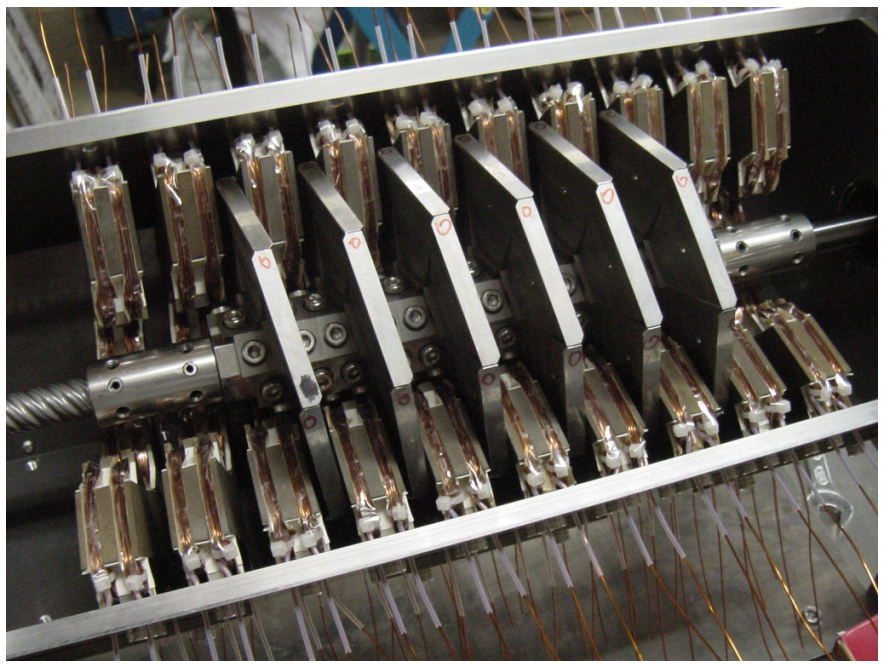

(c)

Fig. 7. Photos of the prototype. (a) Outline of the prototype. (b) Mover block (left) and stator block (right). (c) Inner structure. 


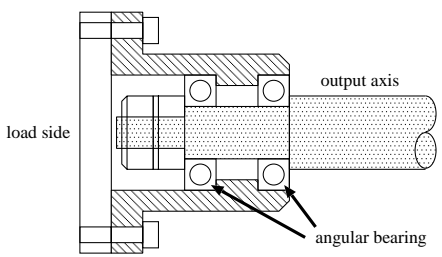

Fig. 8. A rotation canceler for output axis.

\section{B. FEM Analysis}

Static magnetic field of three dimensional CAD model is analyzed by finite element method (FEM). In order to reduce the number of elements in FEM analysis, a half size of the spiral motor is modeled as shown in Fig. 9. This is due to the limitation of computer resources.

Figure 10 shows imposed q-axis current versus calculated thrust force. FEM analysis is carried out for each q-axis current $0,1,2,3,4$, and 5 [A]. A line in this figure is the least-square fitting result. Since the model used in this FEM analysis is a half size, the doubled result is shown in this figure. The resulting thrust force constant is 468 [N/A] as shown in Table II.

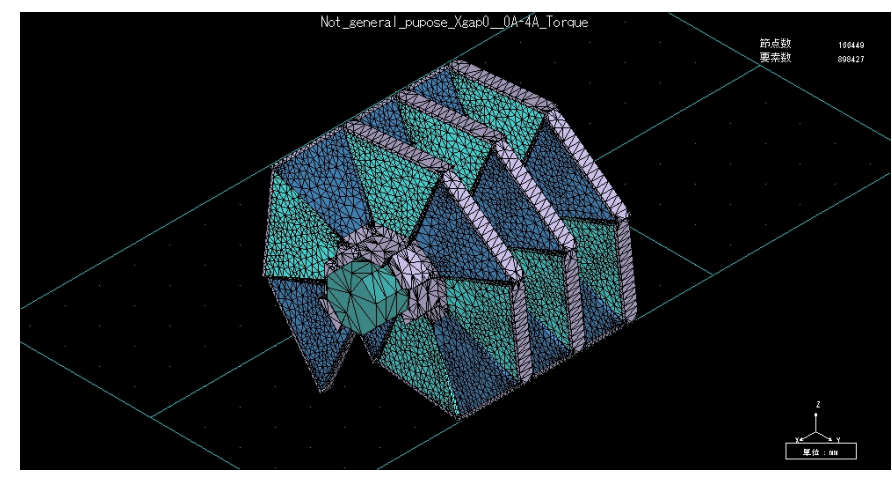

(a)

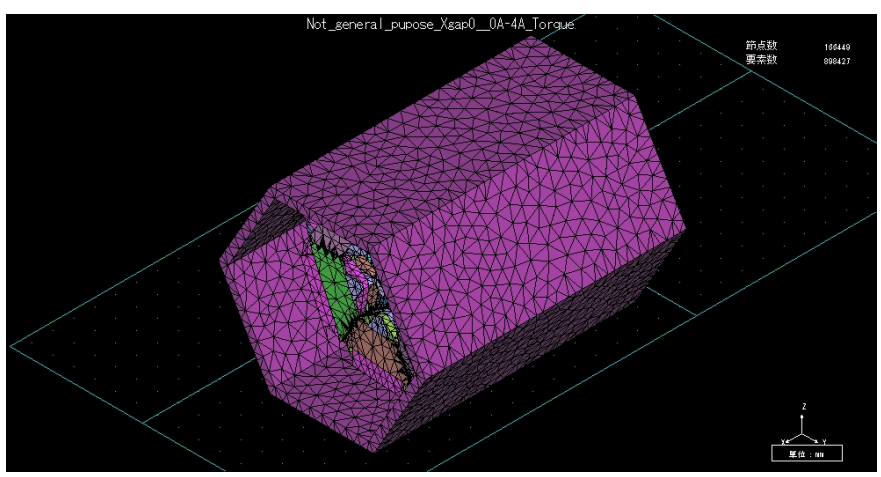

(b)

Fig. 9. Model for magnetic field analysis by FEM. (a) Mover. (b) Stator with frame.

\section{EXPERIMENTS}

\section{A. Experimental Setup}

Figure 11 shows the experimental setup for the developed prototype. An originally developed three-phase inverter with six power-MOSFETs is used to drive the prototype. The

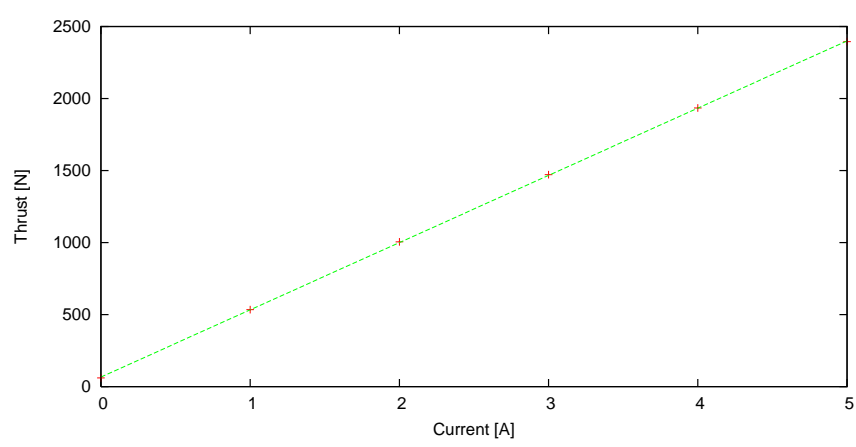

Fig. 10. Thrust force characteristics by FEM analysis. Thrust force constant $K_{f}=468[N / A]$

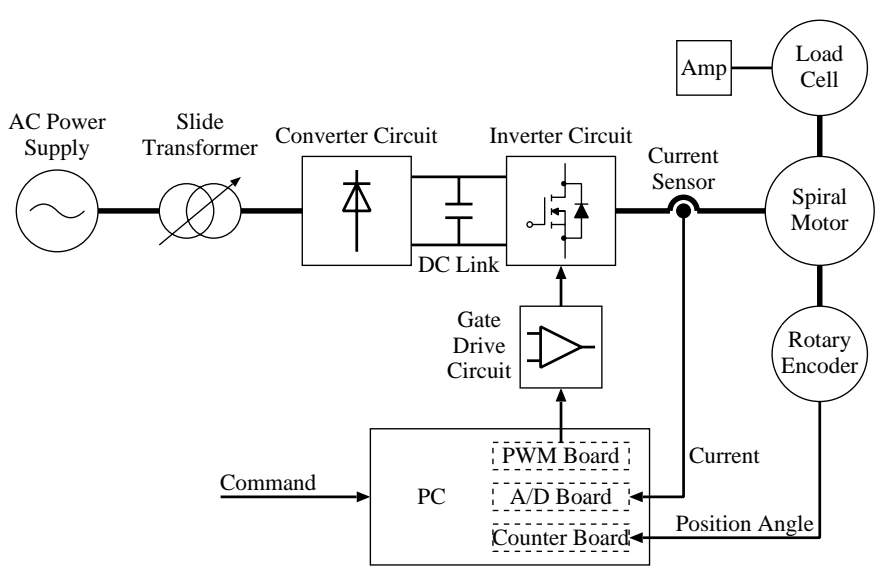

Fig. 11. Experimental setup.

carrier frequency is set to $20[\mathrm{kHz}]$. Three-phase currents are measured by using two current sensors and captured into a PC via an $\mathrm{A} / \mathrm{D}$ converter board at every sampling period. A rotary encoder attached at the mover shaft, type HES-36-2MD made by Nemicon Co., Ltd., generates 3600 pulses per a revolution. A counter board on the PC captures the pulses and accumulates the rotation angle. It is converted into the linear translational position in the PC. Drive signal is transfered from the PC to a gate-drive circuit via a PWM board. A load cell, LUX-A-5KN made by Kyowa Electronic Instruments Co., Ltd., measures thrust force of the motor.

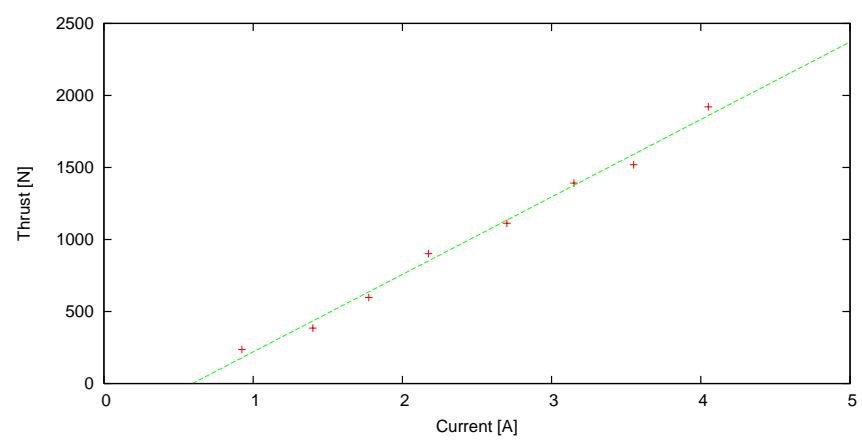

Fig. 12. Measured thrust force characteristics. 


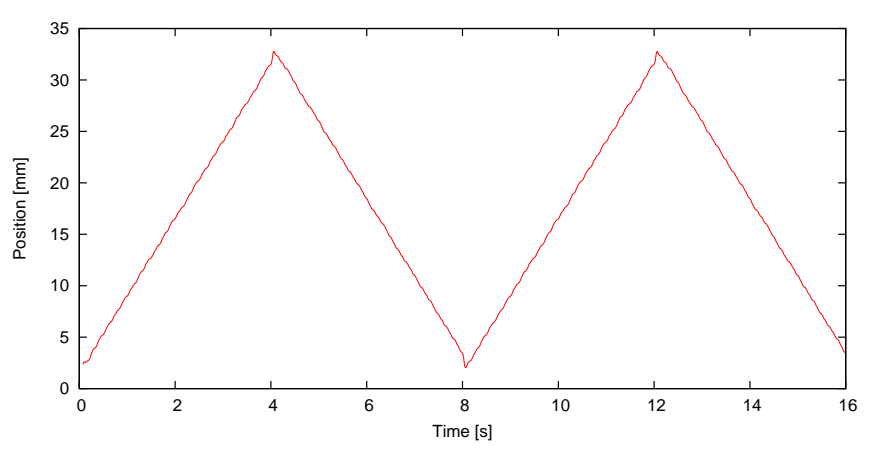

(a)

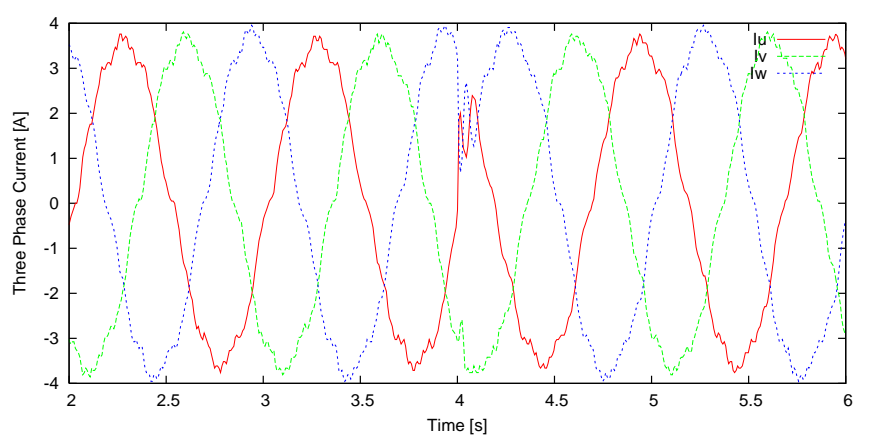

(b)

Fig. 13. Experimental results. (a) Linear position of mover. (b) Three-phase currents.

\section{B. Experimental Results}

Figure 12 shows imposed q-axis current versus measured thrust force. The thrust force was measured by a load cell. A line in this figure is the least-square fitting result. The data are almost on the line. The measured thrust force constant is 538 [N/A]. There is a small deadband under $\left|n I_{q}\right|<0.59$ [A] due to the Coulomb friction of the mechanical system.

The measured thrust force constant is almost close to calculated one by permeance analysis. The thrust force constant by permeance analysis is $10 \%$ more than the measured one. This is because the permeance model ignores permeance of the iron core, leakage flux, and the edge effect.

On the other hand, the thrust force constant by FEM analysis is $13 \%$ less than the measured one. In the FEM analysis, a half model is employed. Therefore, effect of flux leak at the edge of the motor becomes relatively big. This causes the reduction of the thrust force constant.

Then, an experiment of the synchronous drive of the spiral motor is carried out for feasibility study. The reference currents are given by $I_{u}=I_{u}^{\prime}=I_{0} \cos \left(2 \pi f_{r} t\right), I_{v}=I_{v}^{\prime}=$ $I_{0} \cos \left(2 \pi f_{r} t-2 \pi / 3\right)$, and $I_{w}=I_{w}^{\prime}=I_{0} \cos \left(2 \pi f_{r} t-4 \pi / 3\right)$, where $f_{r}=1[\mathrm{~Hz}]$ for $8 m \leq t \leq 8 m+4$ and $f_{r}=-1[\mathrm{~Hz}]$ for $8 m+4 \leq t \leq 8 m+8$ for $m=0,1,2, \ldots$. Figure 13(a) shows the position of the mover under the reciprocating motion. Three-phase currents are shown in Fig. 13(b). These results shows the feasibility of the prototype.
TABLE II

EXPECTED AND MEASURED PERFORMANCE.

\begin{tabular}{lc}
\hline calculated rated thrust force by permeance analysis & $2310[\mathrm{~N}]$ \\
calculated thrust force constant by permeance analysis & $590[\mathrm{~N} / \mathrm{A}]$ \\
calculated thrust force constant by FEM analysis & $468[\mathrm{~N} / \mathrm{A}]$ \\
measured thrust force constant & $538[\mathrm{~N} / \mathrm{A}]$ \\
\hline
\end{tabular}

\section{DISCUSSIONS}

\section{A. Comparison of Thrust Force Capability}

Thrust force per active volume and thrust force per gap area are compared among various linear motors. The active external volume is defined as $\ell_{e} \times S_{e}$ where $\ell_{e}$ is an active armature length and $S_{e}$ is an area of cross section of the motor[12],[22],[24]. If the motor is tubular-type and a radius of the sleeve is $R_{e}$, the area is given by $S_{e}=\pi R_{e}^{2}$. Otherwise, it is simply given by $S_{e}=W \times H$ where $W$ and $H$ are the width and height of the motor. The active armature length $\ell_{e}$ is equal to the length of the outer part when the inner part is longer than the outer part. If the inner armature part is shorter than the outer part, The active armature length $\ell_{e}$ is equal to the length of the inner armature part[12]. The spiral motor is the latter case. From the parameter in Table $\mathrm{I}, l_{e}=q \ell_{p}+\ell_{g}+\ell_{p s}=201[\mathrm{~mm}]$ where $\ell_{p s}=19[\mathrm{~mm}]$ is the length of one stator block as shown in Fig. 3.

The comparison results are shown in Table III. Note that the spiral motor has very wide gap area due to its axial-type motor structure. The thrust force per volume of the spiral motor is higher than HDL motor and 14\% lower than the tubular linear Halbach magnetized PM motor. On the other hand, the thrust force per gap area of the spiral motor is slightly higher than the TL-HPM motor and lower than the HDL motor. It is difficult to obtain straightforward conclusion on superiority or inferiority because various design conditions differ. But it is confirmed that the spiral motor is close to the latest state-of-the-art in linear motor technology. While design optimization of the tubular linear motors are reported in several papers[12],[22] and the prototypes have been built based on these results, the optimal design of the spiral motor is still an open problem.

The thrust force per volume of BSA1, the rotary-motordriven ballscrew system with $10 \mathrm{~mm}$ lead length, is higher than other direct-drive linear motors. However, the thrust gain depends on the lead length of the ballscrew. In comparison with rotary-motor-driven ballscrew systems, an advantage of the spiral motor appears when the ballscrew in the spiral motor is removed. All axial thrust load is supported by magnetic force and only radial load is supported by slide rotary bushes. Then, the motor is applicable for various directdrive applications. Realization of a complete direct-drive spiral motor is our future subject.

\section{B. Comparison of Mover Inertia}

For many applications, low inertia of the mover is also very important. If neutral gap displacement is achieved, i. e., $x_{g}=0$ holds, then an equivalent inertia of the spiral motor is derived as follows. Substituting equations of translation and rotation; $x=\left(\ell_{p} / 2 \pi\right) \theta, \tau=\left(\ell_{p} / 2 \pi\right) f$ into the equation of motion 
TABLE III

COMPARISON OF THRUST FORCE CAPABILITIES. (VALUES IN PARENTHESES ARE ESTIMATED FROM THE ORIGINAL PAPER.)

\begin{tabular}{|c|c|c|c|c|c|c|c|c|c|c|c|c|}
\hline & Proposed & TL-SPM & TL-IPM & TL-HPM & TL-HPM & TL-HPM & HDL & SPM & $\overline{\text { LIM }}$ & HDL & $\overline{\text { BSA1 }}$ & $\overline{\mathrm{BSA} 2}$ \\
\hline Analytically evaluated & - & $\mathrm{x}$ & $\mathrm{x}$ & $\mathrm{x}$ & $\mathrm{x}$ & - & - & - & - & - & - & - \\
\hline Rated thrust force $[\mathrm{N}]$ & 2000 & - & - & - & (254) & 250 & 880 & 139 & 48 & 5000 & 804 & 402 \\
\hline Gap area $\left[\mathrm{mm}^{2}\right]$ & 113,000 & - & - & - & $(15,400)$ & $\leftarrow$ & 22,900 & 8,000 & 11,100 & 60,000 & - & - \\
\hline Gap length $[\mathrm{mm}]$ & 2 & - & - & - & 1 & 1 & 0.2 & 0.5 & 1 & 0.1 & - & - \\
\hline Residual flux density of PM [T] & 1.21 & 1.15 & 1.15 & 1.15 & 1.05 & 1.05 & - & - & - & - & - & - \\
\hline Thrust force per volume $\left[\mathrm{MN} / \mathrm{m}^{3}\right]$ & 0.274 & 0.225 & 0.258 & 0.234 & 0.324 & $(0.318)$ & $\overline{-}$ & - & - & 0.213 & 0.588 & 0.294 \\
\hline Thrust force per gap area $\left[\mathrm{N} / \mathrm{mm}^{2}\right]$ & 0.018 & - & - & - & $(0.017)$ & $(0.016)$ & 0.037 & 0.017 & 0.006 & 0.083 & - & - \\
\hline
\end{tabular}

Abbreviation:

TL-SPM: tubular linear surface-mounted permanent magnet motor

TL-IPM: tubular linear interior permanent magnet motor

TL-HPM: tubular linear quasi-Halbach magnetized permanent magnet motor HDL: high thrust density linear motor

$J\left(d^{2} \theta / d t^{2}\right)=\tau$ where $J$ is the moment of inertia of the mover around axis, we have

$$
\left(\frac{2 \pi}{\ell_{p}}\right)^{2} J \frac{d^{2} x}{d t^{2}}=f
$$

Let the ratio of the mover be $\gamma=\ell_{p m} / \ell_{p}, 0 \leq \gamma \leq 1$ where $\ell_{p m}$ is the length of the mover block as shown in Fig. 3. Assuming that the mass density of the mover is almost uniform, The equivalent moment of inertia $\tilde{J}$ is given by

$$
\tilde{J}=\left(\frac{2 \pi}{\ell_{p}}\right)^{2} J=\frac{2 \pi^{2}}{\ell_{p}^{2}}\left(r_{a}^{2}+\left(r_{b}^{2}-r_{a}^{2}\right) \gamma\right) M
$$

where $M$ is mass of the mover. For the case of the prototype, substituting approximate values $\ell_{p m}=7[\mathrm{~mm}], r_{b}=75[\mathrm{~mm}]$, $r_{a}=19[\mathrm{~mm}]$ into the (25), we have $\tilde{J}=34.9 \mathrm{M}$. The equivalent inertia is about 35 times higher than a linear motor of same mover weight. Hence, the spiral motor results in a heavier equivalent mover and lower acceleration performance than conventional linear motors.

On the other hand, inertia gain is less than the case of rotarymotor-driven ballscrew systems because lead length of their ballscrews is usually shorter than the case of the spiral motor. From (25), the equivalent inertia of the ballscrew system is inversely proportional to the square of the lead length $\ell_{p}$.

\section{CONCLUSION}

A design and analysis of a novel high thrust force linear actuator with spiral structure are presented. A basic model and thrust-force/torque equations are derived by permeance method and the expected performance is shown. Based on this design, the prototype of the spiral motor is developed. FEM analysis and basic experimental results are shown. The thrust force constants obtained by permeance analysis and FEM analysis are almost within $10 \%$ variation of the measured one by experiments. From these experiments, the designed spiral motor achieves $2000[\mathrm{~N}]$ rated thrust force. Comparison of the thrust force capabilities of the spiral motor with other motors is discussed. It is confirmed that the spiral motor is almost close to the latest state-of-the-art in linear motor technology.
LSPM: linear surface-mounted permanent magnet motor LIM: linear induction motor

BSA1: ballscrew actuator with lead length 10 [mm] (THK KLA46 series, 400W) BSA2: ballscrew actuator with lead length 20 [mm] (THK KLA46 series, 400W) *The active external volume of BSA includes only rotary motor and mover.
The proposed motor is expected to be one of the solution for safe and high performance robotic applications. For example, spiral motors are effective to drive a parallel mechanism robot.

\section{REFERENCES}

[1] H. Asada and T. Kanade, "Design of direct-drive mechanical arms," ASME J. of Vibration, Stress, and Reliability in Design, vol. 105, no. 3, pp. 312-316, 1983.

[2] T. Murakami, F. Yu, and K. Ohnishi, "Torque sensorless control in multidegree-of-freedom manipulator," IEEE Trans. Industrial Electronics, vol. 40, no. 2, pp. 259-265, 1993.

[3] S. Katsura, Y. Matsumoto, and K. Ohnishi, "Analysis and experimental validation of force bandwidth for force control," IEEE Trans. Industrial Electronics, vol. 53, no. 3, pp. 922-928, 2006.

[4] S. Katsura, Y. Matsumoto, and K. Ohnishi, "Modeling of force sensing and validation of disturbance observer for force control," IEEE Trans. Industrial Electronics, vol. 54, no. 1, pp. 530-538, 2007.

[5] S. Katsura, K. Irie, and K. Ohishi, "Wideband force control by positionacceleration integrated disturbance observer," IEEE Trans. Industrial Electronics, vol. 55, no. 4, pp. 1699-1706, 2008.

[6] N. Hayashida, T. Yakoh, T. Murakami, and K. Ohnishi, "A sensorless force control in twin drive systems," in Proc. IEEE IECON, pp. 22312236, 2000.

[7] G. Pratt and M. Williamson, "Series elastic actuators," in Proc. IEEE IROS, pp 399-406, 1995.

[8] M. Zinn, O. Khatib, B. Roth, J. K. Salisbury, "Playing it safe," IEEE Robotics and Automation Magazine, vol. 11, no. 2, pp. 12-21, 2004.

[9] A. Bicchi and G. Tonietti, "Fast and "soft-arm" tactics," IEEE Robotics and Automation Magazine, vol. 11, no. 2, pp. 22-33, 2004.

[10] A. Bicchi, M. Bavaro, G. Boccadamo, D. De Carli, R. Filippini, G. Grioli, M. Piccigallo, G. Tonietti, R. Schiavi, and S. Sen, "Physical human-robot interaction: dependability, safety, and performance," in Proc. IEEE AMC, pp. 9-14, 2008.

[11] J. F. Estham, R. Akmese, and H. C. Lai, "Optimum design of brushless tubular linear machines," IEEE Trans. Magnetics, vol. 26, no. 5, pp. 2547-2550, 1990.

[12] N. Bianchi, S. Bolognani, D. D. Corte, and F. Tonel, "Tubular linear permanent magnet motors: an overall comparison," IEEE Trans. Industry Applications, vol. 39, no. 2, 2003

[13] S. M. Jang, J. Y. Choi, S. H. Lee, H. W. Cho, and W. B. Jang, "Analysis and experimental verification of moving-magnet linear actuator with cylindrical Halbach array," IEEE Trans. Magnetics, vol. 40, no. 4, pp. 2068-2070, 2004.

[14] J. Wang and D. Howe, "Design optimization of radially magnetized ironcored, tubular permanent-magnet machines and drive systems," IEEE Trans. Magnetics, vol. 40, no. 5, pp. 3262-3277, 2004.

[15] L. N. Tutelea, M. C. Kim, M. Topor, J. Lee, and I. Boldea, "Linear permanent magnet oscillatory machine: comprehensive modeling for transients with validation by experiments," IEEE Trans. Industrial Electronics, vol. 55, no. 2, pp. 492-500, 2008. 
[16] H-J. Kwon and Y. Fujimoto, "FEM analysis of high thrust spiral motor," in Proc. IEEE AMC, pp. 635-640, 2004.

[17] T. Kominami and Y. Fujimoto, "Magnetic levitation control and spirallinear transformation system for spiral motor," in Proc. IEEE AMC, pp. 529-534, 2006.

[18] Y. Fujimoto and T. Kominami, "Development of a high thrust linear actuator with high backdrivability," in Proc. IEEE AMC, pp. 360-364, 2008.

[19] M. Karita, "High performance technology in linear motor," Journal of the Japan Society for Precision Engineering, vol. 61, no. 3, pp. 347-350, 1995.

[20] Y. Muraguchi, M. Karita, H. Nakagawa, T. Shinya, and M. Maeda, "Method of measuring dynamic characteristics for linear servo motor and comparison of their performance," in Proc. LDIA, pp. 204-207, 1998.

[21] M. Karita, "Linear actuator," JP patent, 2002-027732, 2002.

[22] J. Wang, G. W. Jewell, and D. Howe, "Design optimisation and comparison of tubular permanent magnet machine topologies," IEE Proc Electric Power Applications, vol. 148, no. 5, pp. 456-464, 2001.

[23] J. Wang and D. Howe, "Tubular modular permanent-magnet machines equipped with quasi-Halbach magnetized magnets - part I: magnetic field distribution, EMF, and thrust force," IEEE Trans. Magnetics, vol. 41, no. 9, pp. 2470-2478, 2005.

[24] J. Wang and D. Howe, "Tubular modular permanent-magnet machines equipped with quasi-Halbach magnetized magnets — part II: armature reaction and design optimization," IEEE Trans. Magnetics, vol. 41, no. 9, pp. 2479-2489, 2005.

[25] J. Wang, M. West, D. Howe, H.Z.-D. La Parra, and W. M. Arshad, "Design and Experimental Verification of a Linear Permanent Magne Generator for a Free-Piston Energy Converter," IEEE Trans. Energy Conversion, vol. 22, no. 2, pp. 299-306, 2007.

[26] H. J. Kim, H. Katayama, and K. Maki, "Linear motor and its manufacture," JP patent, 2001-028875, 2001.

[27] M. Rabiee and J. J. Cathey, "Verification of a field theory analysis applied to a helical motion induction motor," IEEE Trans. Magnetics, vol. 24, no. 4, pp. 2125-2132, 1988.

[28] J. J. Cathey and M. Rabiee, "Verification of an equivalent circuit model for a helical motion induction motor," IEEE Trans. Energy Conversion, vol. 3, no. 3, pp. 660-666, 1988.

[29] T. Onuki, W. J. Jeon, and M. Tanabiki, "Induction motor with helical motion by phase control," IEEE Trans. Magnetics, vol. 33, no. 5, pp. 4218-4220, 1997.

[30] J. H. H. Alwash, A. D. Mohssen, and A. S. Abdi, "Helical motion tubular induction motor," IEEE Trans. Energy Conversion, vol. 18, no. 3, pp. 362-369, 2003.

[31] L. Göbel and W. Hofmann, "Control of a rotation-thrust drive with helical motor," in Proc. IEEE IECON, pp. 1343-1348, 1997.

[32] S. M. Jang, S. H. Lee, H. W. Cho, and S. K. Cho, "Design and analysis of helical motion permanent magnet motor with cylindrical Halbach array," IEEE Trans. Magnetics, vol. 39, no. 5, pp. 3007-3009, 2003.

[33] T. Iwasa and H. Satomi, "Linear/rotary combined motor", JP Patent, 2006-311715, 2006

[34] A. Hida, "Spiral motor", JP Patent, 09-056143, 1997.

[35] M. Nakagawa, Y. Asano, A. Mizuguchi, A. Chiba, C. X. Xuan, M. Ooshima, M. Takemoto, T. Fukao, O. Ichikawa, and D. G. Dorrell, "Optimization of Stator Design in a Consequent-Type Bearingless Motor Considering Magnetic Suspension Characteristics," IEEE Trans. Magnetics, vol. 42, no. 10, pp. 3422-3424, 2006.

[36] A. Chiba, D. Akamatsu, T. Fukao, and M. A. Rahman, "An improved rotor resistance identification method for magnetic field regulation in bearingless induction motor drives," IEEE Trans. Industrial Electronics, vol. 55, no. 2, pp. 852-860, 2008.

[37] http://www.thk.com/

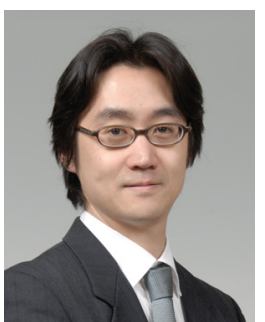

Yasutaka Fujimoto (S'93-M'98) received B.E., M.E., and Ph.D. degrees in electrical and computer engineering from Yokohama National University, Yokohama, Japan, in 1993, 1995, and 1998, respectively. In 1998 he joined the Department of Electrical Engineering, Keio University, Yokohama, Japan as a research associate. Since 1999, he has been with the Department of Electrical and Computer Engineering, Yokohama National University, Japan, where he is currently an associate professor. His research interests include actuators, robotics, manufacturing automation, and motion control. Dr. Fujimoto is a member of IEE of Japan, Robotics Society of Japan, SICE, IEICE and INFORMS.

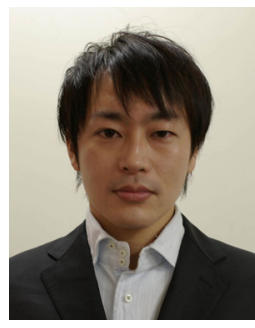

Tsutomu Kominami received B.E., M.E., and Ph.D. degrees in electrical and computer engineering from Yokohama National University, Yokohama, Japan, in 2003, 2005, and 2008, respectively. Since 2008, he has been with Hitachi Research Laboratory, Hitachi, Ltd. His research interests include power electronics and actuators. Dr. Kominami is a member of IEE of Japan and Robotics Society of Japan.

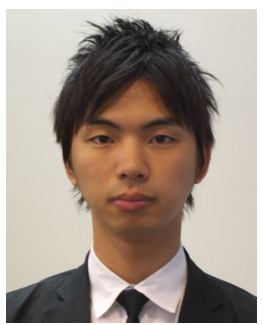

Hiroshi Hamada received B.E. degree in electrical and computer engineering from Yokohama National University, Yokohama, Japan, in 2008, where he is currently working toward the M.E. degree in electrical and computer engineering. His research interest include analysis and control of linear actuators. 